\title{
Correction to: Implementation methods of infection prevention measures in orthopedics and traumatology - a systematic review
}

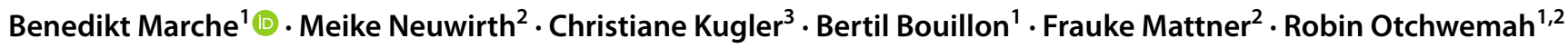

Published online: 9 March 2021

(c) The Author(s) 2021

\section{Correction to: European Journal of Trauma and Emergency Surgery https://doi.org/10.1007/s00068-020-01477-z}

The original version of this article unfortunately contained a mistake.

The affiliations 1 and 2 were incorrect. The correct information is given below.

1 Dept. of Orthopedics, Trauma Surgery and Sports Medicine, University Witten/Herdecke, Cologne Merheim Medical Center, Ostmerheimer Str. 200, 51109 Cologne, Germany.

2 Institute for Hygiene, Cologne Merheim Medical Center, University Hospital University Witten/Herdecke, Ostmerheimer Str. 200, 51109 Cologne, Germany.
The original article has been corrected.

Open Access This article is licensed under a Creative Commons Attribution 4.0 International License, which permits use, sharing, adaptation, distribution and reproduction in any medium or format, as long as you give appropriate credit to the original author(s) and the source, provide a link to the Creative Commons licence, and indicate if changes were made. The images or other third party material in this article are included in the article's Creative Commons licence, unless indicated otherwise in a credit line to the material. If material is not included in the article's Creative Commons licence and your intended use is not permitted by statutory regulation or exceeds the permitted use, you will need to obtain permission directly from the copyright holder. To view a copy of this licence, visit http://creativecommons.org/licenses/by/4.0/.
The original article can be found online at https://doi.org/10.1007/ s00068-020-01477-z.

Benedikt Marche marcheb@kliniken-koeln.de

1 Dept. of Orthopedics, Trauma Surgery and Sports Medicine, University Witten/Herdecke, Cologne Merheim Medical Center, Ostmerheimer Str. 200, 51109 Cologne, Germany

2 Institute for Hygiene, Cologne Merheim Medical Center, University Hospital University Witten/Herdecke, Ostmerheimer Str. 200, 51109 Cologne, Germany

3 Bereich Pflegewissenschaft, Albrecht-Ludwigs-Universität Freiburg, Freiburg, Germany 